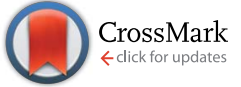

Cite this: RSC Adv., 2017, 7, 14797

Received 16th November 2016 Accepted 27th February 2017

DOI: $10.1039 / c 6 r a 26864 a$

rsc.li/rsc-advances

\section{Spatial-temporal variations, possible sources and soil-air exchange of polychlorinated biphenyls in urban environments in China $\uparrow$}

\author{
Song Cui, ${ }^{a}$ Qiang Fu, ${ }^{\text {a }}$ Yi-Fan Li, ${ }^{\text {,abc }}$ Tian-xiao Li, ${ }^{a}$ Dong Liu, ${ }^{a}$ Wen-cai Dong, ${ }^{a}$ \\ Min Wang a and Kun-yang $\mathrm{Li}^{\mathrm{a}}$
}

Herein, we analyzed and explored the spatial-temporal variations, possible sources, and evaluated soil-air exchange of polychlorinated biphenyls (PCBs) in urban environments in China. For the 11 Chinese cities that were considered in the study, the Spearman correlations of $-0.418(p=0.201)$ for autumn (2004) and -0.797 ( $p=0.003$ ) for spring (2008) between the atmospheric concentrations of PCBs and average temperature were obtained during the sampling period, suggesting that temperature can affect the atmospheric concentrations of PCBs in spring, but not in autumn, which may be driven by comprehensive factors. The Pearson correlation coefficients for the relationship between the concentrations of different PCB homologues among these cities indicate that in 2004 and 2008, the sources of PCBs in the urban atmosphere were different. In 2008, PentaCB to HeptaCB in the atmosphere possibly originated from intentionally produced PCBs (IP-PCBs), whereas DiCB to TetraCB might have been derived from the unintentionally produced PCBs (UP-PCBs) and e-waste (EW-PCBs). These results indicate a shift in the emission sources of PCBs in urban atmosphere from IP-PCBs to a combination of IP-PCBs, UP-PCBs, and EW-PCBs. Moreover, UP-PCBs and EW-PCBs are considered supplementary or major emission sources in the current environment, and thus the reduction and control of UP-PCBs and EW-PCBs should be paid more attention. The results of the study on soil-air exchange of PCBs showed that in 2008, the soil still acted as a sink and the net flux was from air to soil for all the PCB congeners, whereas in 2013-2014, the direction of the net flux was reversed, from soil to air for PCB28 and PCB52, indicating that in 2013-2014, secondary emissions could be an important source of these two PCB congeners.

\section{Introduction}

Polychlorinated biphenyls (PCBs) are one of the main controlled chemicals by the Stockholm Convention on persistent organic pollutants (POPs), ${ }^{\mathbf{1}}$ which are a well-known class of ubiquitous chemicals characterized by their extraordinary stability, extreme toxicity, high ability to undergo long-range atmospheric transport (LRAT), and potential to bioaccumulate in the aquatic and terrestrial food chain system, which poses a threat to both human health and environmental systems., ${ }^{2,3}$

The cumulative global production of commercial PCBs was estimated to be approximately $1.3 \times 10^{6}$ t by Breivik (2002). ${ }^{4}$ PCBs were manufactured in China from 1965 to 1974, and

${ }^{a}$ International Joint Research Center for Persistent Toxic Substances (IJRC-PTS), School of Water Conservancy and Civil Engineering, Northeast Agricultural University, Harbin, Heilongjiang, 150030, P. R. China.E-mail: ijrc_pts_neau_paper@yahoo.com ${ }^{b}$ IJRC-PTS, State Key Laboratory of Urban Water Resource and Environment, Harbin Institute of Technology, Harbin, Heilongjiang, 150090, P. R. China. E-mail: ijrc_pts_hit06@yahoo.com

${ }^{c} I J R C-P T S-N A$, Toronto, M2N 6X9, Canada

$\dagger$ Electronic supplementary information (ESI) available. See DOI: 10.1039/c6ra26864a subsequently, its production was discontinued. Over this period, approximately $10000 \mathrm{t}$ of PCBs were produced (approximately $0.8 \%$ of the total global PCB production). Of these, $9000 \mathrm{t}$ were produced as trichlorobiphenyl, known as Number $1 \mathrm{PCB}$, and $1000 \mathrm{t}$ as pentachlorobiphenyl, named Number 2 PCB. $^{5}$ The proportions of PCBs used in the eastern, central, and western regions of China were $45.2 \%, 35.7 \%$, and $19.1 \%$, respectively. ${ }^{5}$ Trichlorobiphenyl was mainly used in power capacitors and transformers and pentachlorobiphenyl was primarily used as a paint additive. ${ }^{6}$ In general, there are three main types of PCB emission behaviors to the atmosphere, the first of which is the emission due to intentionally produced PCBs (IP-PCBs), the second is the emission of unintentionally produced PCBs (UPPCBs) from industrial thermal processes, and the last is the emission due to dismantling of e-waste and waste electrical and electronic equipment (EW-PCBs). ${ }^{7}$ The production of IP-PCBs in China has been banned for several decades, and these type of emissions began to peak in the early 1990s, as products were disposed of through open burning; later on, the emissions of IPPCBs decreased, but a slight increase has been observed since 2000. ${ }^{7}$ However, Hogarh and coworkers suggested that atmospheric PCB levels might have increased by approximately one 
order of magnitude from 2004 to 2008 across China. ${ }^{8}$ If both the decreasing trend in the IP-PCB emissions and the increasing trend of PCBs concentrations in the air in China were true, what are the reasons that caused the increasing concentrations of PCBs in Chinese air? Normally, the degradation reaction with hydroxyl $(\mathrm{OH})$ radical in the atmosphere plays an important role, which could cause the decreasing trends of PCBs in the environment rather than the increasing trends because the PCBs in air are major from direct emission through usage or volatilization from contaminated soils. Moreover, Totten and coworkers already found evidence for the degradation of PCBs by radicals in urban atmospheres.9,10 The evidence indicated that the magnitude of the depletion for individual PCB congeners has been decreased by approximately $10-20 \%$ for each additional chlorine substituent, and reaction rates with the $\mathrm{OH}$ radical are lower for higher molecular weight congeners.

In their research work, Breivik and coworkers suggested that PCB emissions from e-waste recycling sites and main trade ports, where e-waste was received and dispatched, were responsible for the high concentrations of PCB in some urban areas of China and other developing countries of Asia such as India. ${ }^{\mathbf{1 1 , 1 2}}$ There are some formal and informal e-waste recycling sectors in China, of which, the informal e-waste dismantling areas are located in Guiyu (Guangdong Province), Taizhou (Zhejiang Province), and the formally registered recyclers, which are now actively present in electrical and electronic (EE) manufacturer dense regions such as Tianjin, Beijing, Shanghai, Jiangsu Province and Guangdong Province. ${ }^{13}$ At the same time, four national pilot projects about private recycling plants have been sequentially developed since 2004 .

In our previous study, the gridded UP-PCB emission inventory was compiled and compared with PCB air concentrations measured by our group (IJRC-PTS), and the results successfully explained the increasing concentration of PCBs in rural areas of China with respect to that in urban areas, which may be related to the fact that the number of rural sites monitored across China was higher (the 31 related grid cells include 22 rural sites and 9 urban sites). ${ }^{\mathbf{1 4 - 1 6}}$ Moreover, the IP-PCB emission inventory successfully explained the reason for the increased atmospheric PCB concentrations in urban areas. ${ }^{7}$ According to Hogarh's work, ${ }^{8}$ atmospheric concentration of PCBs increased about one order of magnitude across China from 2004 to 2008, which should raise huge concerns due to the toxicity of PCBs. In fact, the increasing atmospheric concentration of PCBs, which are subsequently transported and transferred from the air to the soil surface via atmospheric particulate deposition or soil-air exchange, could lead to accumulation in soil for a long time; this will affect partitioning, degradation, and transport behavior of individual PCB congener depending on their physicochemical properties and environmental conditions. ${ }^{17}$ Therefore, the objectives of this study were to analyze and explore the spatial-temporal variation and possible sources of PCBs and to investigate their soil-air exchange behavior by coupling atmospheric PCB concentration data with soil PCB concentration data from the same urban areas using the fugacity approach. This study can also provide valuable information for the control of POPs in China and strategies for their reduction.

\section{Methodology}

\subsection{Data sources and compilation}

There have been three national monitoring campaigns for PCBs across China: in 2004 by Jaward et al. $(2005)^{18}$, in 2005 by Zhang (2008, IJRC-PTS), ${ }^{15}$ and in 2008 by Hogarh (2012). ${ }^{8}$ In all these three monitoring programs, the polyurethane foam (PUF) disksbased passive air samplers were used to collect the air samples, in which the PUF disks were retrieved, resealed in their original solvent-cleaned brown glass jars after finishing the sampling period and were stored frozen until extraction in laboratory. ${ }^{\mathbf{8 , 1 5 , 1 8}}$ In the present study, we chose 11 urban sites in China under the first and the third sampling programs since the sampling activities in these two sampling programs were conducted by the same group (the Guangzhou Institute of Geochemistry, the Chinese Academy of Sciences), leading to a strong comparability of the PCB data under these two sampling campaigns. The second program, a concurrent air and soil surface sampling program (SAMP-I) across China was conducted by a different group (IJRC-PTS), ${ }^{15}$ which did not have the same 11 urban sampling sites and thus the data from this campaign were not used in the present study.

In addition, PCB level in Beijing soil measured by Wu et al. $(2011)^{19}$ was used to study the air-soil exchange in 2008 along with the data obtained by Hogarh $(2012)^{8}$, PCB level in Beijing soil in 2014 obtained by Zhang et al. $(2014)^{\mathbf{2 0}}$, and in air in 20132014 obtained by Hong et al. (2015) ${ }^{21}$ were used to calculate the air-soil exchange in 2013-2014, and PCB concentrations in Tianjin air in 2015 obtained by Li et al. (2015) ${ }^{22}$ were used for comparison with the data obtained in 2004 (ref. 18) and 2008 (ref. 8) in Tianjin. Soil organic carbon (SOC) data in Beijing were measured by Guo et al. (2017), ${ }^{23}$ which was $4.63 \%$ in the industrial areas and $4.08 \%$ in the areas surrounding the industrial zone.

China is one of the major global industrial centers, with one of the fastest economic growth rates in the world, and is the world's largest recycler and producer of many electrical appliances containing PCBs. Therefore, the environmental pollution issues accompany with economic development and anthropogenic activities, which have been attracted significant attention from the government and public. To better compare and analyze the differences and characteristics of atmospheric pollution based on the existing datasets, the same sampling sites were selected across China in different periods (in 2004 by Jaward and in 2008 by Hogarh), including the 11 urban sites selected for this study (Fig. 1). These sites were selected to study atmospheric PCB pollution in urban areas and can be associated with the spatial distribution characteristics of PCB use in China. According to China SEPA, $45.2 \%$ of all PCBs in China were used in the east (including Changchun, Shenyang, and Shanghai); $35.7 \%$ were used in the middle region of China (including Beijing, Tianjin, Wuhan, and Nanning); and $19.1 \%$ were used in the west part (including Xi'an, Guiyang, and Kunming). In addition, Hong Kong constitutes a special case 


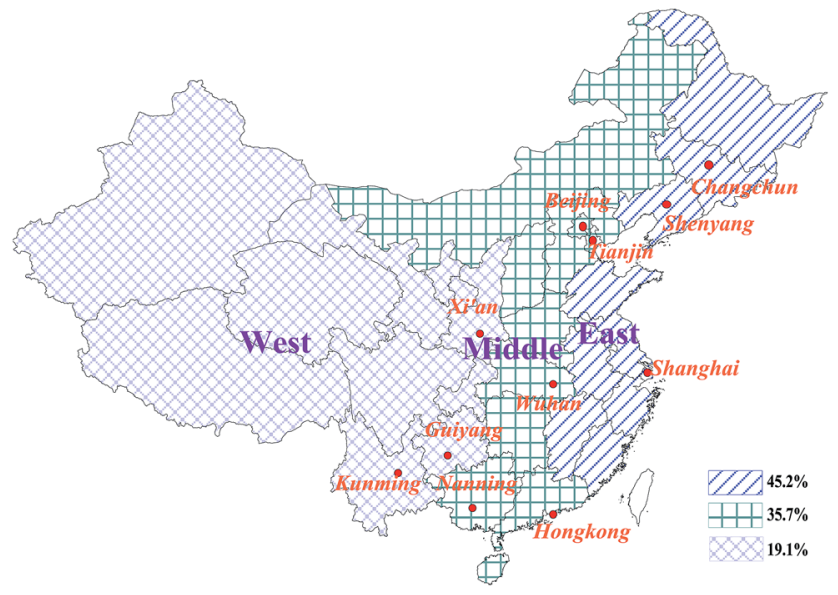

Fig. 1 Spatial distributions of the same sampling sites across China in 2004 and 2008 (ref. 5, 8 and 18) (percentage of PCB use is East: Middle : West $=45.2 \%: 35.7 \%: 19.1 \%$, respectively).

and is not included in the spatial distribution of PCB use in China.

\subsection{Soil-air exchange}

Generally, the soil-air partition coefficient $\left(K_{\mathrm{SA}}\right)$ represents the equilibrium partitioning of a chemical between soil and air. There is a linear relationship between the $K_{\mathrm{SA}}$ and $K_{\mathrm{OA}}$ (octanolair partition coefficient) and to the organic carbon fraction of the soil, which is expressed as follows:

$$
K_{\mathrm{SA}}=\varphi_{\mathrm{SOM}} K_{\mathrm{OA}}
$$

where $\varphi_{\text {SOM }}$ is the mass fraction of SOM (soil organic matter, $\varphi_{\text {SOM }}=\varphi_{\text {OC }} / 0.56$, where $\varphi_{\text {OC }}$ is the mass fraction of SOC (soil organic carbon)) and the values of $K_{\mathrm{OA}}$ as a function of temperature were obtained from Li's study $(2003)^{\mathbf{2 4}}$, which spans generally several orders of magnitude in the range of environmentally relevant temperatures. ${ }^{25}$

Fugacity $(f, \mathrm{~Pa})$ usually describes a chemical's escaping tendency from an environmental medium to another. The fugacity approach was used to investigate the soil-air equilibrium status of organic pollutants. ${ }^{26}$ The fugacity of the PCBs in soil $\left(f_{\mathrm{s}}\right)$ and air $\left(f_{\mathrm{a}}\right)$ were calculated using the equations proposed by some research groups: $:^{27-31}$

$$
\begin{gathered}
f_{\mathrm{a}}=C_{\mathrm{A}} R T \\
f_{\mathrm{s}}=C_{\mathrm{S}} R T / \varphi_{\mathrm{SOM}} K_{\mathrm{OA}}=C_{\mathrm{S}} R T / K_{\mathrm{SA}}
\end{gathered}
$$

where $R$ is the gas constant, $T$ is the temperature in $\mathrm{K}$, and $C_{\mathrm{A}}$ and $C_{\mathrm{S}}$ are the chemical concentrations in air and soil in mol $\mathrm{m}^{-3}$, respectively.

The fugacity fraction (ff) is used to assess equilibrium status of a chemical between soil and air:

$$
\mathrm{ff}=f_{\mathrm{s}} /\left(f_{\mathrm{s}}+f_{\mathrm{a}}\right)=C_{\mathrm{S}} /\left(C_{\mathrm{S}}+K_{\mathrm{SA}} C_{\mathrm{A}}\right)
$$

By adjusting the units, $\mathrm{pg} \mathrm{g}^{-1}$ (dw, dry weight) for $C_{\mathrm{S}}$ and $\mathrm{pg}$ $\mathrm{m}^{-3}$ for $C_{\mathrm{A}}$, using the density of dry soil $\left(\rho_{\mathrm{S}}\right.$ in $\left.\mathrm{g} \mathrm{m}^{-3}\right)$ to convert to volume units, according to empirical studies, ${ }^{28,32}$ we obtained the following modified formula:

$$
\mathrm{ff}=C_{\mathrm{S}} \rho_{\mathrm{S}} /\left(C_{\mathrm{S}} \rho_{\mathrm{S}}+0.41 K_{\mathrm{SA}} C_{\mathrm{A}}\right)
$$

Values of ff equal to 0.5 indicate soil-air equilibrium and no net gas exchange; $\mathrm{ff}>0.5$ indicates net volatilization from soil to air; and $\mathrm{ff}<0.5$ indicates net deposition from air to soil. However, an uncertainty analysis indicated that the value of $\mathrm{ff}$ was between 0.3 and 0.7 as an equilibrium condition..$^{27,28,33}$

\subsection{Coefficient of variation}

The coefficient of variation is defined as the ratio of the standard deviation $\sigma$ to the mean $\mu:^{34}$

$$
C_{\mathrm{v}}=\frac{\sigma}{\mu}
$$

The coefficient of variation is a useful statistical parameter for comparing the variation degree of one data series with another, even if the means are drastically different from each other. In general, a $C_{\mathrm{v}} \leq 0.1$ corresponds to weak variability; 0.1 $<C_{\mathrm{v}}<1$ corresponds to a moderate variability; and $C_{\mathrm{v}} \geq 1$ corresponds to strong variability.

\section{Results and discussion}

\subsection{Spatial and temporal variation}

Air concentration data of PCBs obtained in 2004 and 2008 from the same 11 cities are presented in Fig. 2. The monitoring data indicate that the concentrations of the total PCBs in these areas had increased during the period from 2004 to 2008 , especially in Tianjin..$^{\mathbf{8 1 8}}$ The increased levels of total PCBs are in accordance with the spatial distribution of PCB use in China. There were significant variations of relative growth rate among these cities

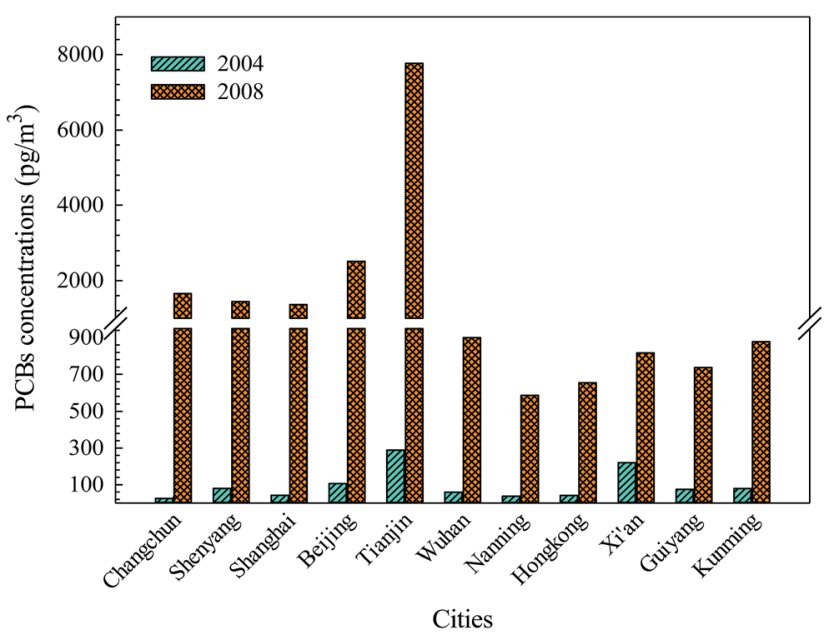

Fig. 2 Air concentration of PCBs in the same 11 cities in 2004 and 2008. 
compared with the growth rate of atmospheric concentration of the total PCBs, and the rate was in the following order: Changchun $(6558.96 \%)>$ Shanghai $(3099.76 \%)>$ Tianjin $(2588.72 \%)>$ Beijing (2285.64\%) > Shenyang (1712.91\%) > Nanning $(1476.38 \%)>$ Hong Kong $(1475.20 \%)>$ Wuhan $(1419.81 \%)>$ Kunming $(1010.79 \%)>$ Guiyang $(889.90 \%)>$ Xi'an $(270.91 \%)$. The existence of point source emissions, atmospheric transport or combined pollution, including IP-PCBs, UP-PCBs and e-waste, could lead to a high growth rate of the total PCBs in these cities. In addition, the meteorological and topographical conditions may have led to a higher growth rate of PCBs in northern and eastern China, including Changchun, Shanghai, Tianjin, Beijing and Shenyang, as the westerlies, East Asian monsoon and local topographical features can affect the atmospheric transport and redistribution patterns of POPs, especially in spring and winter. $^{35}$ The seasonal variations of PCB levels could also be affected by the atmospheric source of the monsoon system. ${ }^{36}$ There are relatively lower growth rates in southern China than in northern China, and this phenomenon may be subjected to the influence of emission sources, degradation reaction with $\mathrm{OH}$ radical, physic-chemical properties of PCBs, meteorological conditions, and urban heat island effect. Generally, the behavior of semivolatile PCBs in the environment strongly depends on the temperature, and temperature can not only affect their volatilization and global distillation effect, but also control their presence in the atmosphere through reactions with $\mathrm{OH}$ radical. This is because increasing the temperature can enhance the reaction rate of PCBs, especially for low-molecular-weight PCBs. Furthermore, dominant gas-phase PCB emissions are also a temperature-controlled process including volatilization of PCBs from local sources at higher temperatures and condensation and deposition of emissions at low temperatures. ${ }^{37}$

Moreover, the sampling period may also affect the atmospheric concentrations of PCBs to some extent because the seasonal or temporal variations can alter the spatial distribution patterns and levels of PCBs in the atmosphere. In fact, the seasonal variations of PCB concentrations in the atmosphere were mainly controlled by the temperature. The sampling times in 2004 (autumn) and 2008 (spring) were different, which could also cause some differences among atmospheric PCB levels in these 11 cities. The seasonal variations of PCBs in the industrial sites showed the highest concentrations of PCBs in spring time. ${ }^{38}$ However, another study showed that the concentrations of PCBs were mainly influenced by the combined effects of reciprocal temperature, wind direction, and wind speed. ${ }^{39}$ To explore the effect of temperature on the occurrence and seasonal variations of PCBs, a Spearman correlation analysis was conducted between the atmospheric concentrations of PCBs and the average temperature during the sampling period in these cities. The analysis provided the following results: $-0.418(p=0.201)$ in autumn $(2004)$ and $-0.797(p=0.003)$ in spring (2008), which suggests that temperature can affect the atmospheric concentrations of PCBs in spring (significant negative correlation), but not in autumn, which may be driven by some factors other than temperature.

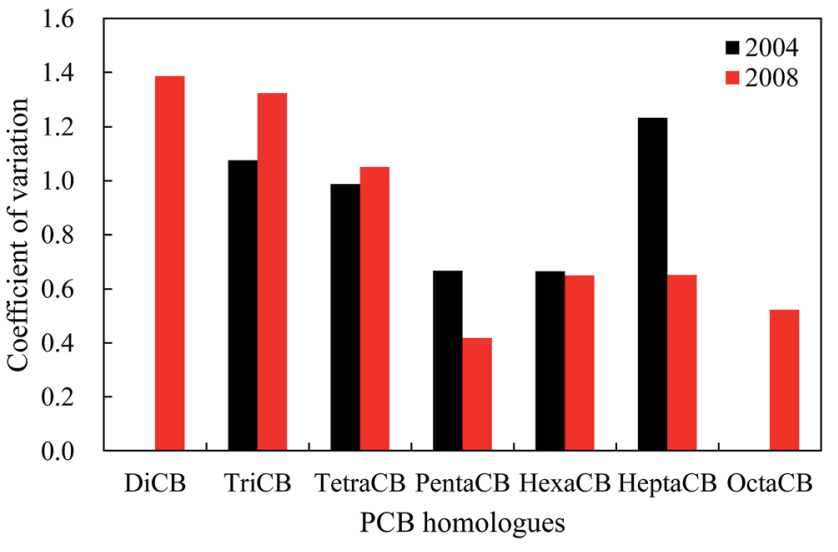

Fig. 3 Coefficient of variation for PCBs in the atmosphere in 2004 and 2008 .

\subsection{Possible sources}

Fig. 3 shows that the PCB homologues corresponded to moderate variability with the exception of HeptaCB and TriCB, which had strong variability in 2004. Especially, HeptaCB presented a large degree of dispersion compared with other PCB homologues, which could originate from point source emissions or spillage. In contrast, there is a lower degree of dispersion for other PCB homologues, which may indicate similar PCB sources. However, the DiCB to TetraCB and PentaCB to OctaCB corresponded to strong variability and moderate variability in 2008, respectively. DiCB to TetraCB had a large degree of dispersion, which might be caused by the disproportion of socioeconomic development and human activities among these 11 cities because the occurrence and levels of PCBs are generally correlated with these factors. On the other hand, the spatial variation patterns of PCB homologues could also reflect the change of emission sources because DiCB to TetraCB are generally regarded as major profiles of UP-PCBs and EW-PCBs in the current environment. ${ }^{\mathbf{4 0 - 4 2}}$ This may explain the contradiction posed by the increased atmospheric concentrations of low-molecular-weight PCBs from IP-PCBs sources despite the fact that low-molecular weight PCBs exhibit a higher degradation rate by $\mathrm{OH}$ radicals.

To explore and elucidate the possible sources of PCBs in the atmosphere, the relationship between the PCB homologues were investigated by examining the Pearson correlation coefficients for the concentrations of the different PCB homologues

Table 1 Pearson correlation coefficients for the relationship between PCB homologues in 2004

\begin{tabular}{llllll}
\hline & TriCB & TetraCB & PentaCB & HexaCB & HeptaCB \\
\hline TriCB & 1 & & & & \\
TetraCB & $0.928^{a}$ & 1 & & & \\
PentaCB & $0.859^{a}$ & $0.953^{a}$ & 1 & 1 & 1 \\
HexaCB & 0.308 & 0.408 & 0.564 & $0.916^{a}$ & 1 \\
HeptaCB & 0.089 & 0.145 & 0.271 & \\
a Correlation is significant at the 0.01 level (2-tailed).
\end{tabular}


Table 2 Pearson correlation coefficients for the relationship between PCB homologues in 2008

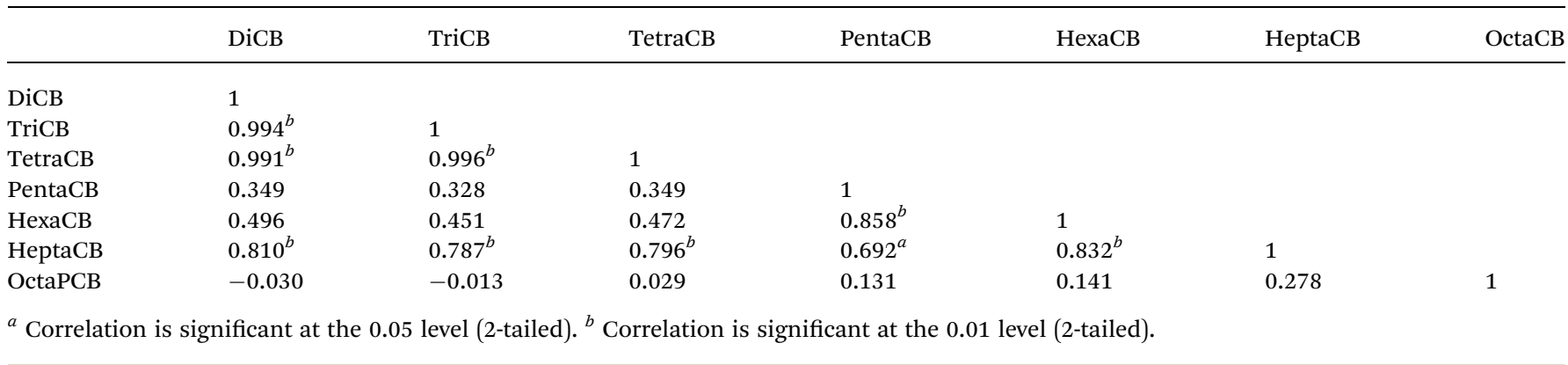

among these cities. In 2004, the concentrations of TriCB, TetraCB, and PentaCB were well correlated among them, and that of HexaCB was correlated with that of HeptaCB (Table 1). However, in 2008, the concentrations of DiCB to TetraCB, PentaCB to HeptaCB, and HeptaCB with DiCB to HexaCB were well correlated (Table 2). These results further reveal that there were different sources of PCBs in the urban atmosphere in 2004 and 2008. In 2008, PentaCB to HeptaCB in the atmosphere may originate from the IP-PCBs compared with DiCB to TetraCB, which could be derived from the UP-PCBs and EW-PCBs. This indicates a shift in the emission sources of PCBs in urban atmosphere from IP-PCBs to a combination of IP-PCBs, UPPCBs, and EW-PCBs.

The compositions of atmospheric PCB homologues among these 11 cities, Aroclor 1242, Aroclor 1254, Chinese products, and UP-PCBs are presented in Fig. 4, which were used to explore the sources characteristics of PCBs in these 11 cities. Fig. 4 shows a high percentage of TriCB in these cities, which could mainly originate from the emissions of IP-PCBs, UP-PCBs and EW-PCBs. This percentage has exceeded as compared to that of PCBs from Chinese products, in which the percentage of TriCB, TetraCB, and DiCB is $41.58 \%, 28.98 \%$, and $12.61 \%$, respectively. ${ }^{43}$ In fact, TriCB is primarily used in electrical appliances and emitted from unintentional production of PCBs. There is a study showing that atmospheric PCBs were dominated by TriCB and TetraCB, and PCB28 was the most abundant congener in electronic waste recycling sites. ${ }^{41}$ Other than that, the percentage of TriCB is more than $60 \%$ of the total PCBs from UP-PCBs. ${ }^{42}$ Therefore, this study can further confirm the complexity of PCB sources in the urban atmosphere through hypothesis between occurrence and degradation of PCBs when only one emission source is considered (IP-PCBs). The degradation processes of PCBs in the atmosphere should be adequately considered due to the existence of $\mathrm{OH}$-radical reaction in the gas phase, which generally appears to be the major removal pathway for atmospheric PCBs. ${ }^{44}$ The study indicated a total loss of up to $8300 \mathrm{t}$ per year through this degradation process. $^{45}$ If the abovementioned hypothesis is true, the composition of PCB homologues will reverse and will not be dominated by low chlorinated PCBs because they are more volatile and degrade in the atmosphere. However, TriCB represents far more than $50 \%$ of the total PCB levels in most cities, as shown in Fig. 4. Hence, UP-PCBs and EW-PCBs are considered as supplementary or major emission sources in the current environment, and this should attract more attention to reduce and control PCBs in the atmosphere.

In addition, the gas-particle partitioning of PCBs can also affect their occurrence and composition in the atmosphere because the gaseous concentrations of PCBs in all the cities were measured through passive air sampling survey. However, this effect may be excluded for the following reasons: first, the sampling period was in spring and autumn when the average temperatures (above $10{ }^{\circ} \mathrm{C}$ ) are higher than those in winter; second, the relatively high proportion of PentaCB with respect to HeptaCB decreased from 2004 to 2008; third, gasparticle partitioning could not prevent high atmospheric levels of high-molecular-weight PCBs, which was verified by monitoring in Hong Kong (Fig. 4). Li and co-author showed that the PCBs had dominant distribution in the gas phase via monitoring ambient air concentrations of an e-waste dismantling area. ${ }^{\mathbf{4 0}}$

\subsection{Soil-air exchange}

Soil-air exchange plays an important role in the regional and global transport and redistribution and determines the current levels and origin of PCBs in soil and air. ${ }^{46-48}$ The concentrations of PCBs in the corresponding environmental medium and their physicochemical properties, soil properties, and gas-particle partitioning in air are generally regarded as significant factors that affect their exchange process between the air and soil. ${ }^{49-51}$ Particularly, the temperature-controlled air-surface exchange was explored, ${ }^{52}$ and the fugacity fractions (ff) of the soil-air exchange were calculated by the fugacity approach to investigate the major sources of atmospheric PCBs and the status of PCBs in air and soil in the current environment. There was very little information available on PCB distribution in urban soil in the 11 cities for 2004 and 2008 and the current year. Therefore, Beijing, which is the largest city in northern China, was selected as a representative city to study the soil-air exchange behavior in 2008 along with the soil concentrations measured by $\mathrm{Wu}$ et al. in Beijing. ${ }^{19}$ In addition, soil-air exchange was also studied for the years 2013-2014 via the air concentration obtained in 2014 (ref. 20) and the soil concentrations obtained in 2013$2014 .{ }^{21}$ Although this may lead to some comparability issues, we expected the data sets to be comparable within a certain range. For 2008, only data for PCB28 was available; thus, this congener was selected to calculate its fugacity fractions (ff) in the same year and the exchange direction for other congeners were 

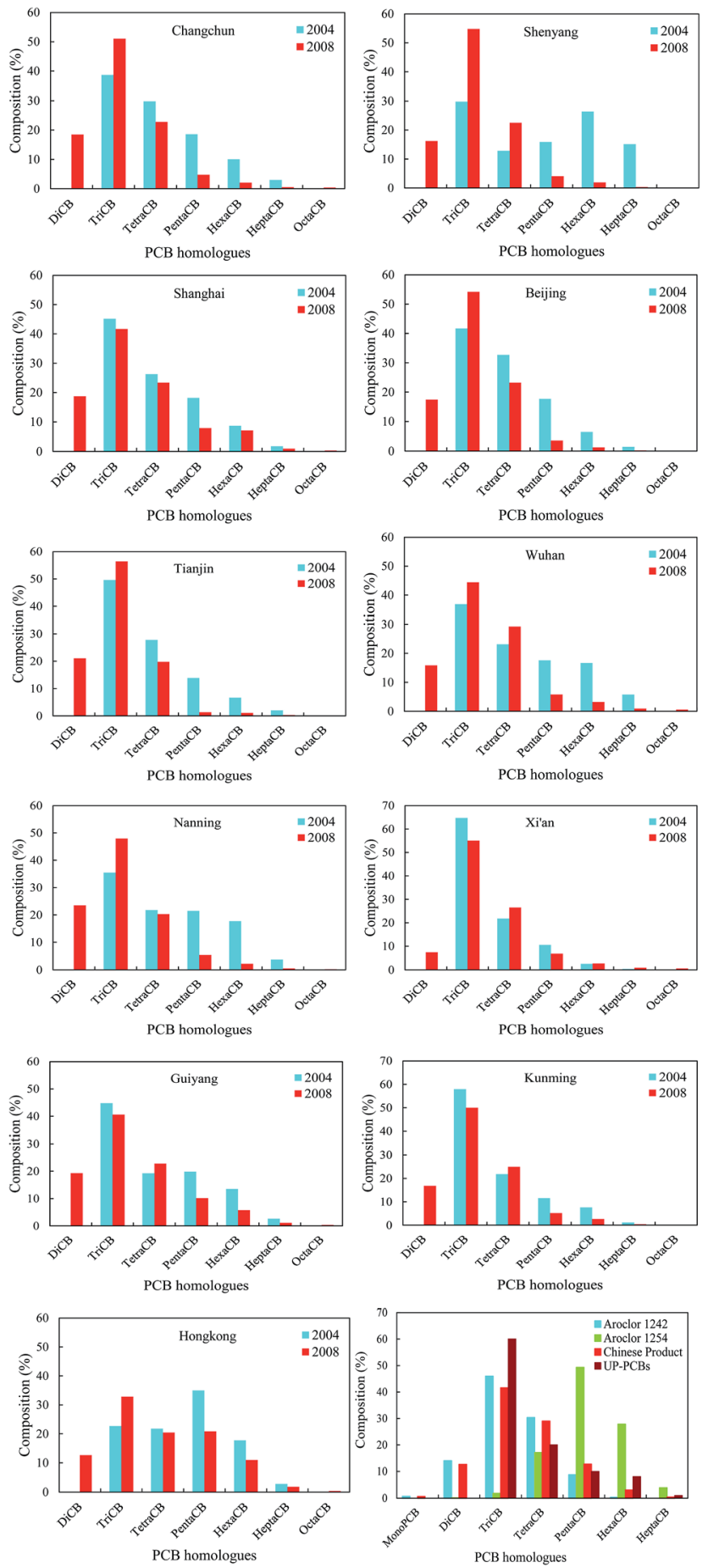

Fig. 4 Composition of PCB homologues in the atmosphere of each of the 11 cities; and in Aroclor 1242, Aroclor 1254, Chinese products, and UP-PCBs.

derived from the results for PCB28. The values of $\mathrm{ff}$ were calculated for indicator PCBs including PCB28, 52, 101, 118, 138,153 , and 180 for Beijing in 2013-2014 and the results are shown in Fig. 5. The concentrations of PCB28 in soil in 2008, and the atmospheric and soil concentrations of PCBs in 20132014 are presented in Fig. A1-A3 (ESI†).

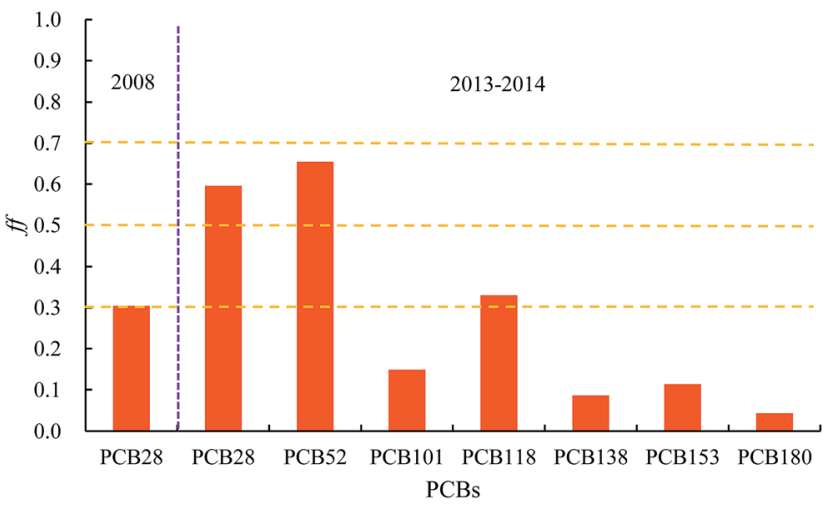

Fig. 5 Fugacity fraction (ff) values for PCB28 in 2008 and indicator PCBs in 2013-2014 in Beijing.

Fig. 5 indicates that the fugacity fractions (ff) are approximately 0.3 , suggesting that the soil acted as a sink and the net flux for PCB28 was from air to soil; thus, secondary emission of PCB28 was not an important source in 2008. The trend of airsoil net flux was most likely the same for other congeners in the same year since PCB28 is the most active chemical among all the congeners discussed in the present study.

In 2013-2014, however, things changed. As shown in Fig. 5, among all the indicator PCBs, the values of ff for PCB28 and PCB52 exceeded 0.5, indicating that the net fluxes for low chlorine-substituted PCB28 and PCB52 was either zero (PCB28 and PCB52 in the air and soil reached equilibrium) or was from soil to air. Thus, the secondary emissions for these 2 compounds started to play an important role as the sources of atmospheric PCBs in urban areas in 2013-2014. For high chlorine-substituted PCBs, the soil still acted as a sink because these congeners have a stronger stability in soil compared with low chlorine-substituted PCB28 and PCB52 and thus have a higher tendency to stay in soil.

In our previous study, the effects of policies on the elimination of PCBs were evaluated. ${ }^{53}$ The results showed that the distinct decrease of PCB levels in the sediment appeared after

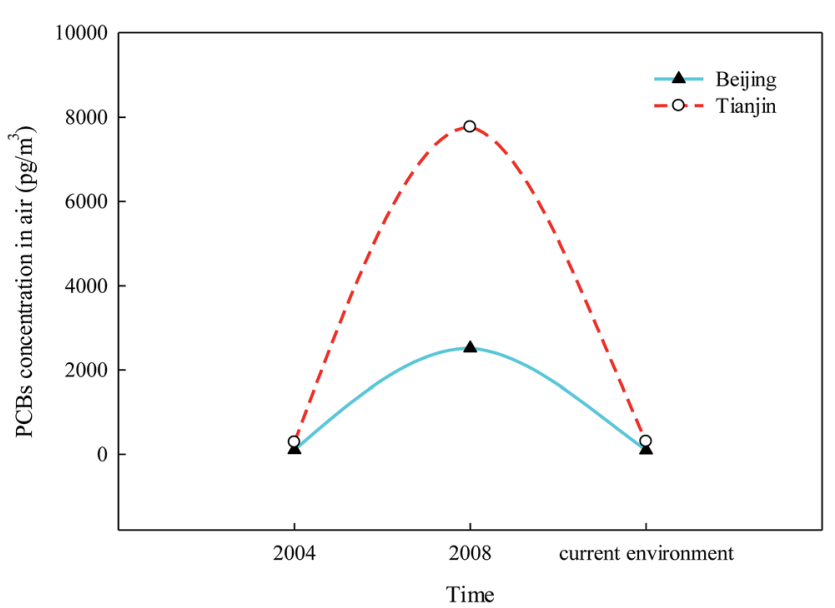

Fig. 6 Temporal trend of the PCBs concentration in air in Beijing $8,18,50$ and Tianjin. $8,18,55$ 
the establishment of the China National Coordination Group for the implementation of the Stockholm Convention. Subsequently, a conceptual reverse management framework for PCBs was established. ${ }^{53}$ Atmospheric PCB levels have distinctly decreased from 2008 in the current environment in Beijing and Tianjin, especially in Tianjin, with a significant decrease from $7766.2 \mathrm{pg} \mathrm{m}^{-3}$ to $307.2 \mathrm{pg} \mathrm{m}^{-3}$ (Fig. 6). Moreover, the increasing PCB11 in the current environment, which is unintentionally produced during the manufacture of pigments and chemical products, should be addressed by the government and researchers $^{54,55}$ (Anezaki and Nakano 2014; Anezaki et al., 2015).

\section{Conclusions}

In summary, 11 cities were selected to investigate and explore the spatial-temporal heterogeneity, possible sources, and soil-air exchange behavior of PCBs in 2004 and 2008. Results show that temperature can affect the atmospheric concentrations of PCBs in spring (significant negative correlation, $R=-0.797, P=$ 0.003 ), but not in autumn, which may be driven by comprehensive factors, including reciprocal temperature, wind direction, and wind speed. The relationship between the concentrations of different PCB homologues among these cities indicated that PCB sources were different in urban areas in 2004 and 2008. In 2008, PentaCB to HeptaCB in the atmosphere may have originated from the IP-PCBs, whereas DiCB to TetraCB may have been derived from the UP-PCBs and EW-PCBs. These results indicate a shift in terms of atmospheric PCB emission sources in urban areas from IP-PCBs to a combination of IPPCBs, UP-PCBs, and EW-PCBs. In addition, UP-PCBs and EWPCBs are considered as supplementary or major emission sources in the current environment, and this should attract more attention for reducing and controlling PCBs in the atmosphere. The results of the study on soil-air exchange shows that the soil acted as a sink for all PCB congeners in 2008, but changed to a source of PSB28 and PCB-53 in 2013-2014. This study constitutes a comprehensive analysis and exploration of PCBs sources in air in the urban areas, which is expected to improve the quality of the environment and avoid the risks for human health.

\section{Conflict of interest}

The authors declare no conflict of interest.

\section{Acknowledgements}

This work was supported by the National Natural Science Foundation of China (No. 41401550), the Natural Science Foundation of the Heilongjiang Province (No. QC2016054), the Young Talents Project of the Northeast Agricultural University (No. 14QC49), and the University Nursing Program for Young Scholars with Creative Talents in the Heilongjiang Province (UNPYSCT-2016001).

\section{References}

1 UNEP, United Nations Environment Programme, Nairobi, Kenya, 2001.
2 M. Mandalakis and E. G. Stephanou, Environ. Pollut., 2007, 147, 211-221.

3 Y. X. Sun, Q. Hao, X. R. Xu, X. J. Luo, S. L. Wang, Z. W. Zhang and B. X. Mai, Chemosphere, 2014, 98, 84-90.

4 K. Breivik, A. Sweetman, J. Pacyna and K. C. Jones, Sci. Total Environ., 2002, 290, 181-198.

5 Y. Xing, Y. L. Lu, R. W. Dawson, Y. J. Shi, H. Zhang, T. Y. Wang, W. B. Liu and H. C. Ren, Chemosphere, 2005, 60, 731-739.

6 China SEPA, Building the Capacity of the People's Republic of China to Implement the Stockholm Convention on POPs and Develop a National Implementation Plan, GEF Project Brief (GF/CPR/02/010), 2003.

7 S. Cui, Q. Fu, W. L. Ma, W. W. Song, L. Y. Liu and Y. F. Li, Sci. Total Environ., 2015, 533, 247-255.

8 J. Hogarh, N. Seike, Y. Kobara, A. Habib, J. Nam, J. Lee, Q. Li, X. Liu, J. Li, G. Zhang and S. Masunaga, Chemosphere, 2012, 86, 718-726.

9 L. A. Totten, S. J. Eisenreich and P. A. Brunciak, Chemosphere, 2002, 47, 735-746.

10 Y. Sun, Q. Zhang and W. Wang, RSC Adv., 2016, 6, 6179461802.

11 K. Breivik, R. Gioia, P. Chakraborty, G. Zhang and K. C. Jones, Environ. Sci. Technol., 2011, 45, 9154-9160.

12 K. Breivik, J. M. Armitage, F. Wania and K. C. Jones, Environ. Sci. Technol., 2014, 48, 8735-8743.

13 X. Chi, M. Streicher-Porte, M. Y. Wang and M. A. Reuter, Waste Manag., 2011, 31, 731-742.

14 N. Q. Ren, M. X. Que, Y. F. Li, L. Y. Liu, X. N. Wang, D. D. Xu, E. D. Sverko and J. M. Ma, Environ. Sci. Technol., 2007, 41, 3871-3876.

15 Z. Zhang, L. Liu, Y. Li, D. Wang, H. Jia, X. Wan, D. Xu, N. Ren, T. Harner, E. D. Sverko, J. Ma and K. Pozo, Environ. Sci. Technol., 2008, 42, 6514-6518.

16 S. Cui, H. Qi, L. Y. Liu, W. W. Song, W. L. Ma, H. L. Jia and Y. F. Li, Atmos. Environ., 2013, 67, 73-79.

17 A. Bozlaker, M. Odabasi and A. Muezzinoglu, Environ. Pollut., 2008, 156, 784-793.

18 F. Jaward, G. Zhang, J. Nam, A. Sweetman, J. Obbard, Y. Kobara and K. Jones, Environ. Sci. Technol., 2005, 39, 8638-8645.

19 S. Wu, X. Xia, L. Yang and H. Liu, Chemosphere, 2011, 82, 732-738.

20 Y. F. Zhang, S. Fu, Y. Dong, H. F. Nie, Z. Li and X. C. Liu, Bull. Environ. Contam. Toxicol., 2014, 92, 466-471.

21 W. Z. Hong, Y. M. Li, L. N. Zhang, J. Bao, P. Wang, C. F. Zhu and Q. H. Zhang, Environ. Chem., 2015, 34, 410-416.

22 Z. Y. Li, P. Zhao and J. H. Zhang, J. Environ. Sci., 2015, 35, 2326-2333.

23 Q. Guo, G. Zhu, T. Chen, J. Yang, J. Yang, M. Peters, R. Wei, L. Tian, X. Han and J. Hu, J. Geochem. Explor., 2017, 175, 1117.

24 N. Q. Li, F. Wania, Y. D. Lei and G. L. Daly, J. Phys. Chem. Ref. Data, 2003, 32, 1545-1590.

25 M. Shoeib and T. Harner, Environ. Sci. Technol., 2002, 36, 4142-4151. 
26 D. Mackay, Multimedia Environmental Models: The Fugacity Approach, Lewis/CRC, Boca Raton, FL, 2001.

27 T. Harner, T. F. Bidleman, L. M. Jantunen and D. Mackay, Environ. Toxicol. Chem., 2001, 20, 1612-1621.

28 S. N. Meijer, M. Shoeib, L. M. Jantunen, K. C. Jones and T. Harner, Environ. Sci. Technol., 2003, 33, 1292-1299.

29 T. F. Bidleman and A. D. Leone, Environ. Pollut., 2004, 128, 49-57.

30 Y. F. Li, T. Harner, L. Liu, Z. Zhang, N. Q. Ren, H. Jia, J. Ma and E. Sverko, Environ. Sci. Technol., 2010, 44, 2784-2790.

31 F. Wong, H. A. Alegria and T. F. Bidleman, Environ. Pollut., 2010, 158, 749-755.

32 M. Hippelein and M. S. McLachlan, Environ. Sci. Technol., 2000, 34, 3521-3526.

33 P. Rưžičková, J. Klánová, P. Čupr, G. Lammel and I. Holoubek, Environ. Sci. Technol., 2007, 42, 179-185.

34 B. S. Everitt, The Cambridge Dictionary of Statistics, Cambridge University Press, Cambridge, UK New York, 1998.

35 Y. Zhang, H. Shen, S. Tao and J. Ma, Atmos. Environ., 2011, 45, 2820-2827.

36 P. Gong, X. P. Wang, J. J. Sheng and T. D. Yao, Atmos. Environ., 2010, 44, 2518-2523.

37 L. Melymuk, M. Robson, P. A. Helm and M. L. Diamond, Sci. Total Environ., 2012, 429, 272-280.

38 J. P. Chen, Q. Wu, H. Y. Xie, J. M. Gu, W. C. Zhao, J. Ma and W. H. Wang, Bull. Environ. Contam. Toxicol., 2007, 79, 448453.

39 S. Harrad and H. J. Mao, Atmos. Environ., 2004, 38, 14371445.

40 Y. Li, G. Jiang, Y. Wang, P. Wang and Q. Zhang, Chin. Sci. Bull., 2008, 53, 521-528.
41 G. H. Xing, J. K. Y. Chan, A. O. W. Leung, S. C. Wu and M. H. Wong, Environ. Int., 2009, 35, 76-82.

42 G. R. Liu, M. H. Zheng, M. W. Cai, Z. Q. Nie, B. Zhang, W. B. Liu, B. Du, S. J. Dong, J. C. Hu and K. Xiao, Chemosphere, 2013, 90, 2453-2460.

43 Z. Zhang, C. G. Tian, H. L. Jia and Y. F. Li, J. Nat. Sci. Heilongjiang Univ., 2010, 27, 111-116.

44 M. Blanchard and M. Chevreuil, J. Atmos. Chem., 2006, 53, 123-144.

45 P. N. Anderson and R. A. Hites, Environ. Sci. Technol., 1996, 30, 1756-1763.

46 F. Wania and D. Mackay, Ambio, 1993, 10-18.

47 K. C. Jones, Environ. Sci. Pollut. Res. Int., 1994, 1, 172-177.

48 C. Backe, I. T. Cousins and P. Larsson, Environ. Pollut., 2004, 128, 59-72.

49 M. D. Borisover and E. R. Graber, Chemosphere, 1997, 34, 1761-1776.

50 I. T. Cousins, A. J. Beck and K. C. Jones, Sci. Total Environ., 1999, 228, 5-24.

51 Y. F. Li, W. L. Ma and M. Yang, Atmos. Chem. Phys., 2015, 15, 1669-1681.

52 C. J. Halsall, B. Gevao, M. Howsam, R. G. M. Lee, W. A. Ockenden and K. C. Jones, Atmos. Environ., 1999, 33, 541-552.

53 S. Cui, Q. Fu, L. Guo, Y. F. Li, T. X. Li, W. L. Ma and W. L. Li, Mar. Pollut. Bull., 2016, 106, 109-118.

54 K. Anezaki and T. Nakano, Environ. Sci. Pollut. Res., 2014, 21, 998-1009.

55 K. Anezaki, N. Kannan and T. Nakano, Environ. Sci. Pollut. Res., 2015, 22, 14478-14488. 